pork-barrel amendments are irrelevantly tagged onto legislation with quite different purposes.

British parliamentarians, who profess distaste for the way that US congressmen ambush unconnected legislation to serve the needs of their constituents, should reflect carefully on what was done last week. Since 1990, both research and medical procedures using human embryos have been strictly regulated by a statutory authority, the Human Fertilization and Embryology Authority. The only complaints which there have been of the authority is of its tendency to officiousness. Earlier this year the authority put out a consultation paper which fairly outlined the pros and cons of using ova taken from aborted fetuses as well as from stillborn children and women who have died. The consultation period (extended because of the volume of comment) is due to end in July.

Evidently Mrs Jill Knight MP, a long-serving member of the House of Commons, cannot wait for that process to be complete. Having failed, earlier this year, to win parliamentary time for a bill to ban the use of fetal ova in IVF, she had sought to tag a similar provision onto this year's Criminal Justice and Public Order Bill now making its way through the British parliament. That is fair enough. The surprise is that Bottomley should have announced during the proceedings that she would be voting for the amendment. That is a bad business, and a serious dereliction of duty by a government minister, whatever her personal opinion about the rights and wrongs of the use of fetal ova.

This is why. First, there is no prospect that the HFEA will sanction the use of fetal ova in IVF while its consultation is still under way. Second, it is unthinkable that such proposals would be approved while it is not known why the number of ova in a female fetus is ordinarily reduced by more than four orders of magnitude by the time of ovulation; the possibility that the discarded ova are genetically impaired would first have to be excluded. Third, the consultation has itself raised an important issue that would have to be decided before anything could be done; existing British guidelines on the use of fetal tissue allow consent to be given by the mother alone and require that the purpose should not be specified, while the law under which HFEA operates's requires that IVF procedures should be genetically transparent. Fourth, there is no need of legislation: failure to comply with the HFEA's licence terms is already a criminal offence.

Bottomley knows that, and should have said so. Her failure to do so is bound to undermine the authority of the HFEA, whose consultation process has been made to seem largely irrelevant. But the terms of her endorsement of the amendment are also alarming: Mrs Knight's advocacy of her cause had "hit a nerve". Yet Mrs Bottomley's own interest as a minister is that such matters should not be decided emotively. The best hope now is that the House of Lords, which will have another chance to say what it thinks of the bill, will throw out the amendment on the grounds that it is superfluous. Meanwhile, the whole shabby incident is yet another reminder that Britain needs better parliamentary procedures.

\section{How to lose confidence}

The scandal over fraudulent data in a breast-cancer study undermines trust in the research establishment.

LAST month the Chicago Tribune reported that some participants in a major study of lumpectomy plus radiation versus total mastectomy for early breast cancer did not meet the study's protocol. And worse: research physicians coordinating the study at the University of Pittsburgh as well as its overseers at the National Cancer Institute (NCI) had known about the aberrations since 1991. The Office of Research Integrity also knew about the faulty data, as did officials at the Food and Drug Administration. But no one said a word.

Roger Poisson, a breast-cancer surgeon at St Luc's Hospital in Montreal, falsified the records of at least a hundred women in the surgical study and also submitted falsified data in that part of it meant to evaluate the drug tamoxifen as adjuvant therapy. Poisson admits enrolling women who were technically ineligible, in some cases because they had not made a decision about surgery within 30 days of diagnosis as specified in the research protocol. More than 450 hospitals, caring for some 5,000 women, have contributed data. A preliminary analysis, excluding Poisson's data, confirms that lumpectomy is every bit as effective as more radical total mastectomy in treating early breast cancer.

But that is not the point. Every day, hundreds of women all over the world make decisions based on the conclusions of this study, which until last month was headed by Bernard Fisher, a Pittsburgh surgeon who has devoted more than 20 years changing the long-standing belief in radical mastectomy. And now those women have lost confidence in the US government. It does not matter that statistical analysis says the data hold up. What matters is that everyone who bears any responsibility for the study knew about the aberrant data and no one spoke up, probably from a well-intentioned but paternalistic instinct not to upset women needlessly.

What should Fisher and the others have done? The answer is easy. As soon as they learned that Poisson had failed to follow the protocol, they should have excluded him from the study with a public announcement to that effect. They could have added that the aberrant data in no way changed the presumption in favour of lumpectomy, but that a scientist who tampers with the data, however benignly, will not be tolerated. They should have known that the fraud would eventually come out - it always does - and that newspaper accounts of a cover-up would do far more damage to the public trust than a clear statement about a single surgeon who thought he could bend the rules and get away with it.

Last week, Samuel Broder, head of the NCI, and Harold Varmus, the new director of the National Institutes of Health, found themselves in the embarrassing position of apologizing to Congress for their silence (see page 679). At a hearing before Representative John Dingell (Democrat, Michigan), they tried to put the blame on Fisher. But in this case, there is plenty of blame to go around and everyone (except Varmus, who is too new) should accept his share. 